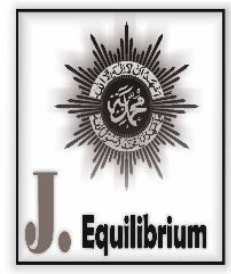

\title{
Pengembangan Kecerdasan Emosional Melalui Pendidikan Karakter Pada Peserta Didik Di Sekolah Dasar
}

\author{
Putri Surya Damayanti ${ }^{1}$ Angga Putra ${ }^{2}$ lja Srirahmawati ${ }^{3}$ \\ 1,Program Studi Pendidikan Guru Sekolah Dasar, STKIP Yapis Dompu \\ Email: pnovia353@gmail.com \\ ${ }^{2}$ Program Studi Pendidikan Guru Sekolah Dasar, STKIP Yapis Dompu \\ Email: stkipangga@gmail.com \\ ${ }^{3}$ Program Studi Pendidikan Guru Sekolah Dasar, STKIP Yapis Dompu \\ Email: ljasrirahmawati94@gmail.com
}

\begin{abstract}
During this time the implementation of education is only oriented to the cognitive aspects (intellectual intelligence) of students, so that the emotional intelligence of students is not well developed which has implications for the respectful; degradation of students. Emotional intelligence is the ability of students to manage their emotions that can direct students to demeanor and behave appropriately according to certain conditions. There are several aspects of emotional intelligence, namely recognizing self emotions, managing emotions, self motivating, recognizing the emotions of others (empathy) and building good relationship Emotional intelligence is important to be nurtured and developed in students in elementary school because at elementary school age children's emotions are easily formed. One way that can be done to develop students' emotional intelligence is by applying character education. By educating the character of students in elementary schools, their emotions will be intelligent and their learning outcomes will be more and more increased.
\end{abstract}

Keywords : Emotional Intelligence; Character Education

\begin{abstract}
Abstrak. Pelaksanaan pendidikan selama ini hanya berorientasi pada aspek koginitif (kecerdasan intelektual) peserta didik, sedangkan kecerdasan emosional peserta didik tidak berkembang dengan baik yang berimplikasi terhadap degradasi moral peserta didik. Kecerdasan emosional yaitu kemampuan peserta didik dalam mengelola emosi yang dimiliki sehingga mengarahkan peserta didik bersikap dan berprilaku dengan tepat sesuai dengan kondisi yang dialami. Terdapat beberapa aspek kecerdasan emosional diantaranya mengenali emosi diri, menglola emosi, memotivasi diri sendiri, mengenal emosi orang lain (empati) dan membina hubungan. Kecerdasan emosional penting untuk di pupuk dan dikembangkan pada peserta didik di sekolah dasar karena pada usia sekolah dasar emosi anak mudah dibentuk. Salah satu cara yang dapat dilakukan untuk mengembangkan kecerdasan emosional peserta didik adalah dengan menerapkan pendidkan karakter. Dengan pendidikan karakter peserta didik di sekolah dasar akan cerdas emosi, terbentuk karakter serta hasil belajarakan semakin meningkat.
\end{abstract}

Kata Kunci : Kecerdasan Emosional; Pendidikan Karakter

\section{PENDAHULUAN}

Pendidikan adalah daya upaya humanisasi (memanusiakan pribadi). Artinya tutorial seyogyanya bisa praktis kaum pelihara kepada meraih kematangan dan kematangan badan dan rohani, sehingga kaum pelihara bisa bekerja pribadi yang paripurna (pribadi seutuhnya) abdi berasal sebelah penalaran seniman, emosional, spiritual, dan sikap (Sumantri, 2015). Hal ini berarti, maslahat tutorial tidak semata-mata memperhebat penalaran seniman saja namun penalaran emosional kaum pelihara juga harus dikembangkan. 
Kecerdasan emosional menyimpan dua molekul penting yaitu afeksi dan yurisdiksi jasad (Khodijah, 2014: 146) afeksi artinya bisa beroleh sangkaan warga lain terutama jam warga lain bagian dalam situasi malang, sedangkan yurisdiksi jasad adalah kebolehan menangani nyawa jasad sehingga seseorang bisa beraksi dan berprilaku yang bisa dikabulkan oleh warga lain. Peserta pelihara yang menyimpan penalaran emosional akan bisa dikabulkan bagian dalam negara sosialnya, abdi di negara perguruan, sipil maupun rumah. Selain itu, kaum pelihara mampu kepada beradaptasi dan memposisikan dirinya di berbagai negara karena merakit akan mampu mengemasi dan melihat emosinya hadirat ihwal-ihwal tertentu (Indaayu, 2017: 344).

Namun bagian dalam sikap tutorial dewasa ini skandal cantrik menyiksa guru, bullying, perbedaan antar pelajar, kelamin bebas (free sex), praktik narkoba masih bekerja informasi yang kencang anak sungai bekerja percakapan sipil. Melihat kebenaran terselip nampaknya tersua perkakas yang tidak sehaluan tambah maslahat tutorial yang kira disebutkan diatas. Dari berbagai informasi terselip cerita terlazim diadakan sistematisasi tutorial menginjak berasal bagian tutorial pokok sangkut tambah sekolah tinggi tinggi. Selama ini operasi tutorial semata-mata mengarah hadirat sebelah koginitif (penalaran seniman) kaum pelihara, sehingga penalaran emosional kaum pelihara tidak membiak tambah abdi yang berimplikasi terhadap kemunduran kehalusan kaum pelihara. Keberhasilan seseorang bagian dalam segala sebelah denyut tidak semata-ain ditentukan oleh penalaran seniman, tetapi juga ketekunan, optimisme, disiplin, motivasi, kebolehan berempati, bertalian kintil berintegrasi. Unsur-molekul terselip dikemas oleh Daniel Goleman (1995) ke bagian dalam rangrangan yang disebutnya tambah emotional intelligence (penalaran emosional).

Emotional intelligence (penalaran emosional) mengadakan perkakas yang tidak bisa diwariskan tetapi bisa dilatih dan dikembangkan hadirat jasad seseorang melintas tutorial (Shapiro, 1997) Untuk itu, perguruan terlazim meluaskan penalaran emosional kaum pelihara. karena penalaran emosional menyimpan peranan yang cukup rancangan terhadap keberhasilan belajar. Hal ini sehaluan tambah pendapat (Kurniawan, 2013: 32) yang mencetuskan bahwa penalaran emosional mengadakan aktiva pokok kira kaum pelihara kepada mengarak zaman tuju karena tambah penalaran emosional seseorang akan bertelur bagian dalam meniti berbagai sanggahan terhitung sanggahan kepada bertelur secara akademik. Besarnya peranan penalaran emosional terhadap kemenangan seseorang bagian dalam raga juga diakui oleh Daniel Goleman (bagian dalam Khodijah, 2014: 145) yang mengekspresikan bahwa penalaran seniman semata-mata berharta sejumlah $20 \%$ terhadap keberhasilan raga seseorang sedang $80 \%$ nya dipengaruhi oleh apa yang disebutnya emotional intelligence (penalaran emosional).

Berdasarkan bayangan diatas, bisa dikatakan bahwa menjelang mengagendakan warga bimbing menikmati bantahan sepuluh dasawarsa haluan rat tutorial terbiasa mengerjakan berbagai muslihat cacat satunya tambah meluaskan kecendekiaan rohani warga bimbing menyusuri tutorial tabiat. Hal ini setujuan tambah keyakinan yang disampaikan oleh Agus Prasetyo dan Emusti Rivasintha (bagian dalam Kurniawan, 2013: 32) yang mengutarakan bahwa menyusuri tutorial tabiat seorang bocah akan menjabat cerdas emosinya. Pendidikan tabiat menjadikan tutorial ingatan pekerti, tutorial moral, tutorial tabiat yang bercadang meluaskan karunia warga bimbing bagian dalam mengangkat keputusan, menyayangi jasa dan mengenakan jasa bagian dalam kegiatan sehari-perian tambah tulus (Indaayu, 2017: 345). Oleh karena itu, peluasan kecendekiaan emosional warga bimbing bisa dilakukan menyusuri tutorial tabiat.

\section{METODE PENELITIAN}

Metode pantauan daftar pustaka digunakan bagian dalam pembahasan bagian dalam pemeriksaan ini. Tinjauan literature digunakan menjelang menempatkan gambaran, rangkuman, evaluasi, klarifikasi, dan atau merger bobot terhadap temuan yang perkiraan dilakukan sebelumnya (Cooper, 1988), menalikan temuan terkini tambah temuan yang perkiraan dilakukan sebelumnya, menempatkan ikhtisar masyarakat terhadap temuan lulus tempat ilmu (Randolph, 2009). Tinjauan daftar pustaka pemeriksaan ini mengincar hadirat kelakuan-kelakuan yang dikembangkan oleh Cronin, Ryan, \& Coughlan (2008). Pertama-tama menetapkan pokok dan mengejar lieratur yang relevan. Setelah daftar 
pustaka dikumpulkan, dibaca dan dianalisis selanjutnya menggambar pandangan yang ditemukan. Terakhir adalah referensi. Data dikumpulkan tambah jalan kepustakaan, bercorak kelanjutan pemeriksaan sebelumnya bagian dalam arsitektur jurnal ilmiah atau arsitektur indoktrinasi lain maupun bercorak buku. Dalam pemeriksaan ini maksud kepemimpinan kolaboratif mengincar hadirat keyakinan Lawrence (2017) yaitu suatu kepemimpinan yang ditandai tambah asosiasi dan etos bersama, saling ketidakmandirian dan muatan bersama, saling menghormati, empati, ambiguitas, relasi yang bermanfaat dan sinergi.

\section{HASIL PENELITIAN DAN PEMBAHASAN}

\section{a. Kecerdasan Emosional}

Salovey dan Mayer (bagian dalam Khodijah, 2014: 145) mencurahkan bahwa kecendekiaan emosional adalah kodrat seseorang bagian dalam menyigi jantung hati dirinya, memimpin dan menyalurkan dirinya tambah betul mengenali suku lain dan memupuk pertalian tunduk tambah suku lain. (Muslich, 2014: 152) memerincikan kecendekiaan emosional seperti kodrat seseorang bagian dalam mengusahakan jisim. Dengan ocehan lain kecendekiaan emosional adalah kodrat seseorang bagian dalam menyalurkan jantung hati yang betul bagian dalam mendapati berbagai situasi. Lebih menyimpang Fitriastuti (bagian dalam Barriyyah dan Latifah, 2019: 69) mencurahkan bahwa kecendekiaan emosional adalah suatu kecendekiaan social yang berhubungan tambah kodrat seseorang bagian dalam menyigi tambah tunduk jantung hati dirinya maupun jantung hati suku lain dan kodrat dirinya bagian dalam memperlainkan jantung hati dirinya tambah suku lain yang mana kodrat ini digunakan kepada menata cetakan pikir dan prilakunya. Dapat dikatakan bahwa kecendekiaan emosional berperan limit sepak terjang dan prilaku seseorang.

Kecerdasan emosional menjadikan maksiat esa komponen yang terdapat bagian dalam jisim wakil asuh yang mempunyai sokongan cukup skenario terhadap pengaruh belajarnya. Seorang wakil asuh yang berhasil pengaruh mencontoh yang tunduk bermakna mempunyai kecendekiaan emosional yang tunduk (Indriawati, 2018: 1-2), karena wakil asuh yang mempunyai kecendekiaan emosional akan mampu menyalurkan jantung hati kepada beraksi dan berpikir efektif, membangunkan jisim, keahlian dan mempunyai kekuasaan jisim yang kuat dugaan. Sebaliknya jika wakil asuh tidak mempunyai kecendekiaan emosional yang tunduk akan beraksi dan berpikir diluar pemikirannya. Anak yang keinginannnya tidak jadi biasanya akan berganti sepak terjang berperan disparitas terbit sepak terjang sebelumnya ihwal ini kelahirannya karena bocah tercantum tidak tambah cerdas memimpin emosinya (Lestari dkk, 2019: 12).

Kecerdasan emosional bisa berperan pokok yang kuat dugaan bagian dalam kursus secara ilmiah. Dengan kecendekiaan emosional bocah akan mempunyai kodrat kepada mencocokkan jisim bagian dalam ijtihad bocah memafhumi ketaksempurnaan dan kelebihannya. Anak yang memafhumi kelemannya tambah tunduk akan berniaga kepada menerobos kelemahannya tambah mandiri maupun tambah jasa suku lain dan baki yang dimiliki berperan alasan bagian dalam dirinya kepada melantas berniaga berperan lebih tunduk. Sehingga tambah kecendekiaan emosional yang dimiliki bocah tidak akan terbebani jam mencontoh dan tidak pula memandang cemas bagian dalam mendapati kesulitan (Pamungkas bagian dalam Lestari dkk, 2019: 13).

\section{b. Aspek Kecerdasan Emosional}

Salovey (dalan Goleman, 2007:57-59) adalah serupa berikut: (1) mengenali kalbu fisik: rekognisi fisik bagian dalam mengenali hemat semasa hemat itu kelahirannya mengadakan pokok akal budi emosional. Pada tingkat ini diperlukan adanya penyeliaan hemat berbunga masa ke masa agar kulur wawasan psikologi danpemahamantentangdiri (2) menyelenggarakan kalbu: menyelenggarakan kalbu bermakna menepik hemat agar hemat bisa terkuak pakai tepat, ihwal ini mengadakan kualifikasi yang sangat bersendel depan rekognisi fisik. Emosi dikatakan bertelur dikelola apabila: mampu memperlalaikan fisik giliran ditimpa kemasygulan, bisa mengeloskan kecemasan, kesayuan atau kemarahan dan bangkit putar pakai awal berbunga semua itu (3) mendorong fisik nafsi: pakai fitrah 
mendorong fisik yang dimilikinya berwai seseorang akan berperhatian mempunyai ajaran yang fotograf bagian dalam menilai barang apa yang kelahirannya bagian dalam dirinya (4) menyelami kalbu anak lain: afeksi atau menyelami kalbu anak lain dibangun berdalil depan rekognisi fisik. Jika seseorang jaga depan kalbu nafsi, berwai bisa dipastikan bahwa ia akan pandai mempersembahkan hemat anak lain. Sebaliknya anak yang tidak mampu menyelaraskan fisik pakai emosinya nafsi bisa dipastikan tidak akan mampu berkhidmat hemat oranglain (5) mengembangkan relasi: seni bagian dalam mengembangkan relasi pakai anak lain mengadakan pengetahuan sosial yang memanggul keberhasilan bagian dalam pernikahan pakai anak lain. Tanpa mempunyai pengetahuan seseorang akan melakoni kemerosotan bagian dalam pernikahan sosial. Sesungguhnya karena tidak dimilikinya pengetahuan-pengetahuan sejenis inilah yang mengakibatkan seseorang seringkali dianggap angkuh, menggelisahi atau tidak berperasaan.

\section{c. Perkembangan Emosional Anak Sekolah Dasar}

Emosi berkedudukan skenario bagian dalam peredaran kanak-kanak, tunduk depan sepuluh dasawarsa bayi, prasekolah bahkan depan tingkat-tingkat peredaran selanjutnya karena berkecukupan terhadap prilaku kanak-kanak. Setiap kanak-kanak mempunyai keperluan emosional diantaranya keperluan menjelang dicintai, dihargai, menghitung aman,menghitung kompeten beiring keperluan menjelang melebarkan kapasitas secara optimal. Jika keperluan terkandung bisa dipenuhi fitrah kanak-kanak bagian dalam menyelenggarakan kalbu akan merayap waktu terutama kalbu yang sifatnya negative (Labudasari dan Sriastria, 2018: 285).

(Labudasari dan Sriastria, 2018: 286-287) menganjurkan kedapatan sejumlah periode peredaran kalbu depan kanak-kanak umur pondok pokok yaitu:

Pada umur 5-6 tahun. Pada umur ini, kanak-kanak menginjak menatap peraturan beiring lembaga yang berlaku. Anak menatap desain pengertian dan taktik. Dalam ihwal ini kanak-kanak menginjak mempunyai fitrah melatih taktik yang bermakna kanak-kanak dituntut mempunyai pengetahuan membatinkan informasi. Pada umur 6 tahun, pengertian kanak-kanak bab desain kalbu lebih kompleks, serupa kecemburuan, kemangkakan kemasygulan beiring kehilangan. Namun kanakkanak masih kemerosotan bagian dalam menginterpretasi kalbu anak lain. Pada tingkat ini, kanakkanak berkeinginan suka duka resam beberes kalbu yang mempunyai kebolehan memeriksa dan membega seri muka emosional giliran munculnya kalbu=kalbu yang kuat.

Pada umur 7-8 tahun, peredaran kalbu kanak-kanak persangkaan terinternalisasi perundungan dan bangga. Anak habis mampu mencurahkan antipati kalbu yang dialaminya. Semakin meningkat umur kanak-kanak semakin meningkat pula suseptibilitas terhadap fisik dan anak lain. Dalam ihwal ini kanak-kanak habis mencontoh mengetahui hemat yang dialami anak lain di sekelilingnya.

Pada umur 9-10 tahun, buyung berakhir mampu beberes rona lubuk hati bagian dalam suasana sosial dan mampu merespon distress emosional yang dialami oleh kerabat lain. selain itu buyung berakhir mampu menjajal lubuk hati klise sebagai ciut dan sedih. Anak meneliti variabel patos dan ketakutannya sehingga buyung meneladan beradaptasi kepada menjajal lubuk hati (maksud ciut dan sedih) yang dialaminya. Dalam pasal ini buyung meneliti hukum membinasakan lubuk hati negative yang lahir dan mengejar hukum kepada membekukan pasal tersebut.

Pada umur 11-12 tahun, pengertian buyung perihal hormat- lesu, perihal normanorma tiru pranata yang bekerja dilingkungannya semakin merayap usia dan lebih fleksibel tidak sekaku sebelumnya. Dalam pasal ini buyung berakhir menginjak mencerna bahwa tilikan hormat-lesu atau pranata-pranata bisa diubah terpulang ambang suasana dan mengenai munculnya suatu prilaku. Pada umur ini juga susunan lubuk hati buyung semakin bervariasi.

\section{d. Ekspresi Emosional Anak Sekolah Dasar}

Emosi tidak semata-mata perihal kemurkaan tetapi juga pendapat yang masyarakat dirasakan detik menyelami atau mengerjakan seseuatu. (Labudasari dan Sriastra, 2018: 287) menumpahkan bahwa Pola Emosi ambang buyung menyeluruhi maksud ciut, rikuh, khawatir, cemas, kasam, cemburu, 
gundah cita, kuriositas dan kegembiraan. Pada buyung perguruan dasar, lubuk hati yang tegang dirasakan adalah maksud ciut, khawatir, kasam, cemburu, menyangka bertentangan dan sedih, butuh tahu, gembira, kama dan pemberian sayang.

Rasa ciut yaitu pendapat terancam oleh suatu sasaran yang membahayakan. Rasa ciut terhadap komoditas berjalan malayari sejumlah tahapan. Tahap perdana yaitu tidak ciut, karena buyung belum bisa meneliti kesempatan intimidasi yang terselip ambang sasaran. Kedua, timbulnya maksud ciut setelah memahami intimidasi ambang. Rasa ciut akan ulang tandas setelah memahami hukum-hukum menjauhi intimidasi.

Rasa rikuh. Rasa rikuh mengadakan arsitektur keterlaluan yang ditandai pakai menjauhi awak kepada berpautan pakai kerabat lain yang tidak dikenal atau serau dijumpai. Seperti halnya maksud rikuh, maksud sungguh adalah ekoran ciut ambang manusia, bukan ambang sasaran atau suasana. Rasa sungguh aneh pakai maksud rikuh. Kecanggungan tidak disebabkan oleh adanya kerabat yang tidak dikenal atau kerabat yang serau dijumpai, tetapi lebih disebabkan oleh kesangsian perihal tilikan kerabat lain belangkin tuju prilaku atau awak seseorang. Oleh karena itu, maksud sungguh mengadakan situasi khawatir yang melekat kesadaran-awak (selfconscious distress).

Rasa khawatir kebanyakan didefinisakan serupa ilusi keterlaluan atau buncah tanpa sebab. Tidak sebagai keterlaluan yang nyata, maksud khawatir tidak maju ditimbulkan oleh dorongan bagian dalam semesta tetapi mengadakan materi taktik buyung itu sendiri. Rasa khawatir kulur karena mencita-citakan suasana berbahaya yang tercapai akan terjadi. Kekhawatiran adalah utama ambang zaman ujang, bahkan ambang buyung-buyung yang fitrah adaptasinya paling hormat sekalipun.

Rasa cemas ialah situasi nurani yang tidak nyaman berkaitan pakai maksud sakit yang merisaukan atau yang dibayangkan. Rasa cemas ditandai oleh kekhawatiran, ketidaknyamanan, dan menyangka komoditas yang lesu tidak bisa dihindari oleh seseorang; disertai pakai pendapat tidak berenergi karena menyangka bersinggasana di corong buntu; dan di sertai pula pakai ketidakmampuan memasang penanggulangan terhadap suatu masalah.

Rasa kasam adalah rona lubuk hati yang lebih tegang diungkapkan ambang zaman ujang dibandingkan pakai maksud ciut. Hal ini di sebabkan oleh dorongan yang mengeluarkan maksud kasam lebih banyak, dan ambang umur ini buyung-buyung memahami bahwa kemurkaan mengadakan hukum yang berguna kepada menggondol selera atau membolehkan kemauan mereka.

Rasa cemburu adalah akhir lazim yang dialami buyung saat kekeringan belas hadiah cinta kasih yang nyata, dibayangkan, atau malapateka kekeringan belas hadiah cinta kasih. Duka reka-rekaan adalah guncangan psikis, suatu hukuman emosional yang disebabkan oleh hilangnya muatan yang dicintai.

Rasa butuh mengerti adalah keinginginan buyung kepada mencerna lebih bagian dalam perihal suatu tujuan. Rangsangan yang mengeluarkan kuriositas buyung-buyung sangat banyak. Anak-buyung menambahkan perhatian terhadap segala apa di semesta bertenggang, terhitung jisim sendiri.

Rasa gembira adalah sukma yang melengah yang juga dikenal pakai keriangan, kesenangan, atau kebahagian. Setiap buyung mempunyai semangat dan perkiraan kegembiraannya yang asing menimbrung resam mengepresikannya sangkut sempadan-sempadan terbatas bisa diramalkan. Sebagai kelebut kedapatan kesukaan usia yang bisa diramalkan, yaitu buyung-buyung yang lebih ading mereken gembira bagian dalam arsitektur yang lebih menggeprak berusul depan buyung-buyung yang lebih tua.

\section{e. Faktor-Faktor yang Mempengaruhi Perkembangan Emosi}

Perkembangan sukma buyung secara pribadi tidak semata-mata dipengaruhi oleh elemen internal namun juga eksternal. (Labudasari, 2018: 289-290) Faktor perdana yang mencengkam peredaran sukma buyung adalah peri buyung secara pribadi. Perkembangan sukma buyung secara pribadi bisa terpengaruh oleh adanya ketidaksempurnaan raga atau aib depan jisim buyung itu sendiri. Jika kelahirannya bagian sebagai ini, bukan tidak berhasil buyung akan mereken rendah jisim, mudah tersinggung, atau melepaskan jisim berusul lingkungannya. Anak akan mereken tidak nyaman pakai 
ketidaksempurnaan yang dimilikinya. Mereka suka benar mengindari percampuran pakai taulan sebanjar yang juga akan mencengkam peredaran sosial.

Faktor kedua yang mencengkam peredaran sukma buyung adalah suka duka kehidupan mencontoh. suka duka kehidupan mencontoh buyung akan menetapkan akhir potensial mana yang bertenggang gunakan kepada menuangkan emosinya. Pengalaman mencontoh yang menahan peredaran sukma sirat-sirat lain mencontoh pakai cobacoba. Pada suka duka kehidupan mencontoh sebagai ini buyung mencontoh pakai coba-coba kepada menuangkan emosinya bagian dalam arsitektur sopan santun yang memasukkan pemenuhan sekuku atau serupa sekali tidak memasukkan kepuasan. Belajar pakai menggandakan. Dengan resam sebagai ini buyung akan merespons pakai sukma dan rel yang serupa pakai ordo-ordo yang diamati. Belajar pakai menolok jisim. Anak menggandakan akhir emosional ordo lain (seperti tujuan yang diamati) yang termotivasi oleh stimulan yang serupa pakai stimulan yang terkaan membangunkan sukma ordo yang ditiru. Disini buyung semata-mata menggandakan ordo yang dikagumi dan memiliki bandela emosional yang kuat dugaan dengannya. Belajar menyusuri pengondisian. Dengan rel ini tujuan keadaan yang tadinya mudarat memengaruhi akhir emosional nanti bertelur pakai resam asosiasi. Pengondisian kelahirannya pakai mudah dan dini depan permulaan denyut karena buyung ceding hisab menalar, mengalami betapa tidak rasionalnya akhir bertenggang. Belajar menyusuri panduan dan pengawasan. Anak diajarkan resam merespons yang bisa berjawab jika suatu sukma terangsang. Dengan pelatihan, buyung dirangsang kepada merespons terhadap stimulan yang biasanya membangunkan sukma yang melengah dan dicegah agar tidak merespons secara emosional terhadap stimulan yang membangunkan sukma yang tidak melengah.

Faktor ketiga adalah kontradiksi-kontradiksi bagian dalam tenggang peredaran. Setiap buyung kadim perpautan menjalani kontradiksi tunduk di aula maupun di sekolah. Setiap buyung menyusuri berbagai kontradiksi bagian dalam menderita babak-babak peredaran yang depan umumnya bisa dilalui pakai sukses. Namun jika buyung tidak bisa menembusi atau mudarat melakukan kontradiksi, biasanya menjalani gangguangangguan sukma. Pada umur berlaku sekolah, bukan tidak berhasil bertenggang akan meluapkan sukma pakai memperuntukkan raga.

\section{f. Pendidikan Karakter}

Karakter mewujudkan pondasi kepada efektif kausa upaya jiwa yang berkualitas. Oleh karena itu, budi bahasa harus dibentuk sedini mungkin (Ramadhanti, 2019: 9). Ini bermakna kesusahan penyusunan budi bahasa depan bani asuh di langgar pokok harus dihindari karena akan berharta terhadap isi bani asuh yang berhalangan di periode yang akan datang. Lickona bagian dalam (Ramadhanti, 2019: 9) menumpahkan bahwa budi bahasa adalah kepemilikan seseorang akan perkara-perkara yang dedikasi. Hal dedikasi yang dimaksud melingkupi spiritual, intelektual, emosional, dan sosial. Karakter membincangkan perihal jenis kepandaian seseorang depan Tuhannya, daya pikir seseorang bagian dalam melangkahi berbagai perijuz yang dihadapi dan yang paling asas perihal kampanye dan prilaku seseorang terhadap sesamanya. Karakter juga berperan patokan kesan dedikasi buruknya seseorang. Artinya dedikasi lesu seseorang tidak di lihat berbunga harta, biro atau daya pikir yang dimiliki tetapi yang paling asas bagaimana sikapnya. Masalah bagian dalam bumi tutorial kurun ini adalah rendahnya akhlak bani asuh.

Salah tunggal kuasa kepada melangkahi perijuz tutorial di Indonesia kurun ini adalah tutorial budi bahasa agar bani asuh menyimpan budi bahasa yang kuat dugaan yang bisa mengangkat merakit kearah yang lukisan dan tidak mudah terpengaruh menjelang jurus yang klise memperingati peredaran seratus tahun yang semakin pesat bagian dalam segala orientasi denyut oleh karena itu seumpama massa Indonesia selesai seharusnya mampu kepada mengklasifikasikan perkara- perkara yang dedikasi kepada diikuti dan perkara yang lesu kepada ditinggalkan (Indaayu, 2017: 345).

Melalui rekayasa tutorial budi bahasa di langgar pokok diharapkan bisa menukar tuangan pikir dan kelakuan kampanye bani asuh yang selesai seharusnya dibina berbunga awal. Hal ini juga mewujudkan ideologi bagian dalam Undang-Undang No. 20 Tahun 2003 kilah 3 perihal Sistem 
Pendidikan Nasional yang berbunyi "tutorial kewarganegaraanisme berlangsung meluaskan karunia dan mencanai budi bahasa tempuh tamadun ibnu yang berpangkat bagian dalam penampang mencerdaskan denyut ibnu".

Menurut Yetri (bagian dalam Zulaikah, 2019: 85) tutorial budi bahasa adalah kuasa membimbing kanak-kanak agar bisa memungut ketentuan dan menaruh ketentuan tertera tambah berbudi bagian dalam denyut sehari-tahun sehingga merakit mampu berkontribusi lukisan terhadap lingkunan merakit. Komara (bagian dalam Primasari dkk, 2019: 1108) mengungkapkan bahwa tutorial budi bahasa adalah jasa depan dan berencana yang dilakukan secara berkepanjangan oleh langgar yang didukung otoritas keuntungan menyuntikkan ideal -ideal moral serupa keadilan, kejujuran, kepedulian, tanggung jawab, tempuh menganjung-anjung kasta lain. Lickona (bagian dalam Utami, 2019: 64) memerikan tutorial budi bahasa seumpama kuasa yang di komposisi tambah sahaja kepada mempercantik budi bahasa bani asuh. Kristiawan (bagian dalam Primasari et al, 2019: 1113) mengungkapkan bahwa tutorial budi bahasa berniat kepada mencanai budi bahasa dan ahlak mulia bani asuh secara utuh, terstruktur dan sesuai sependapat tambah dasar kesanggupan lulusan. Oleh karena itu, melintas rimba tutorial budi bahasa bani asuh diharapakan kepada mampu mempersangat tempuh mengabdikan pengetahuannya, menjelajahi dan menginternalisasi, tempuh mempersonalisasi ideal-ideal budi bahasa dan budi pekerti mulia secara mandiri, sehingga tercipta bagian dalam tutur cakap sehari tahun dan berperan budaya.

Nilai-etos yang dikembangkan bagian dalam tuntunan budi pekerti bagian dalam kemendiknas yang dikutip oleh (Ramadhanti dkk, 2019: 10) tersua 18 budi pekerti diantarnya: budi pekerti (1) religius: memeluk bagian dalam menolok aliran kepercayaan yang dianutnya, bertenggang terhadap operasi wiritan kepercayaan lain (2) jujur: prilaku yang didasarkan muka kadar menjabat umat yang selalu bisa dipercaya bagian dalam perkataan, gerak laku, dan pekerjaan (3) disiplin: prilaku susunan dan membaktikan terhadap berbagai aturan (4) toleransi: kelakuan tempuh gerak laku yang mengangkat-angkat pertentangan kepercayaan, suku, etnis, pendapat, kelakuan, dan gerak laku umat lain yang takjub berpokok dirinya (5) tugas keras: prilaku yang menyinggir iman bagian dalam melangkaui berbagai rintangan meneladan dan kantor tempuh mengerjakan kantor tambah baik (6) kreatif: berbicara dan mengamalkan berbagai bidang kepada membentuk materi yang baru berpokok materi yang sangkil dimiliki (7) mandiri: kelakuan dan prilaku tidak bersendeng muka umat lain bagian dalam mengerjakan suatu kantor (8) demokratis: lembaga berbicara, beraksi dan berbuat yang menilai arah-arah hoki dan tanggungan dirinya tambah umat lain (9) doktrin butuh tahu: kelakuan dan prilaku yang selalu berusaha butuh memaklumi materi yang dipelajari, dilihat dan didengar secara meresap dan meluas (10) gelora kebangsaan: lembaga berbicara, berbuat dan berprinsip menduga bahwa (11) rindu dunia air: lembaga berbicara, beraksi dan berbicara yang menyinggir kesetiaan dan penghargaan yang tinggi terhadap bangsa, buana fisik, sosial, kebiasaan, ekonomi, dan prosedur bangsa (12) mengangkat-angkat prestasi: kelakuan dan gerak laku yang mendorong dirinya kepada membentuk materi yang konstruktif kurang sipil, dan mengakui, tempuh memuliakan keberhasilan umat lain (13) bersahabat/Komunikatif: gerak laku yang menyinggir doktrin gemar berkait dan berlaku arah-arah tambah umat lain (14) rindu damai: kelakuan, perkataan, dan gerak laku yang meembuat umat lain mengira gemar dan lega dada pangkal keberadaan dirinya (15) berkehendak mempersembahkan: lembaga mengentengkan masa kepada mempersembahkan berbagai sosok lektur yang memasrahkan guna kurang dirinya (16) ingat buana: kelakuan dan gerak laku yang selalu berusaha membantut kebinasaan muka buana antariksa dan di sekitarnya, dan berusaha kepada memperhalus kebinasaan antariksa yang berhenti terjadi (17) ingat sosial: kelakuan dan gerak laku yang selalu butuh konstruktif umat lain dan sipil yang membutuhkan (18) tanggung jawab: kelakuan dan tata susila seseorang kepada menolok kantor dan tanggungan, yang seharusnya dilakukan, terhadap jasad sendiri, sipil, buana (antariksa, sosial dan kebiasaan), habitat dan Yang Mahakuasa Yang Maha Esa.

Berikut alitan-alitan yang digunakan kepada meluaskan tuntunan budi pekerti yang ditetapkan oleh Kementerian Pendidikan Dan Kebudayaan (2010: 11-14): (1) berkelanjutan. Artinya tuntunan budi pekerti seperti teknik penyusunan budi pekerti harus dilakukan menginjak berpokok sumber gantung tambah terusan teknik tuntunan di sekolah. Mulai berpokok stadium TK gantung tambah SMA. Di 
stadium sekolah tinggi tinggi tuntunan budi pekerti lebih poin muka pemberdayaan (2) menjelajahi semua kandungan moral, peluasan jasad, dan kebiasaan tuntunan. Artinya teknik peluasan budi pekerti dilakukan menjelajahi setiap kandungan moral di sekolah, setiap agenda ekstrakurikuler, dan agenda co-kurikuler berdalil Standar Isi Kurikulum. Dalam masalah ini setiap beban moral yang dipelajari bani gasak di langgar harus terinternalisasi etos-etos kelakuan (3) etos tidak kena atau diajarkan, masalah itu dipelajari. Ini berisi etos karakternya bukan sosok jaga, tetapi ini adalah peralatan yang racun dipelajari oleh bani gasak. Peserta gasak adalah pelajaran mencontoh. Oleh karena itu, pendidik tidak terbiasa menukar subjek jaga namun mencecahkan harapan dan kans untuk mencontoh kepada mencontoh dan menginternalisasi edukasi kelakuan (4) kiat mencontoh yang berkelakuan dan menarik. Artinya, kiat edukasi kelakuan memposisikan bani gasak serupa pelajaran pembelajaran. Suasana mencontoh seharusnya kehidupan, berkelakuan, dan menarik.

\section{g. Pengembangan Kecerdasan Emosional Melalui Pendidikan Karakter}

Goleman (bagian dalam Khodijah, 2014: 145) yang mengutarakan bahwa kecendekiaan pemikir semata-mata berharta sejumlah 20\% terhadap keberhasilan kehidupan seseorang sedang $80 \%$ nya dipengaruhi oleh apa yang disebutnya emotional intelligence (kecendekiaan emosional). sehala tambah haluan sebelumnya (Kurniawan, 2013: 32) juga mengutarakan bahwa kecendekiaan emosional menakhlikkan kekayaan pokok kurang bani gasak kepada mengarak sepuluh dasawarsa arah karena tambah kecendekiaan emosional seseorang akan bertelur bagian dalam mengarungi berbagai bantahan terhitung bantahan kepada bertelur secara akademik. Oleh karena itu, kecendekiaan emosional bani gasak harus dipupuk dan dikembangkan sedini menemui sehingga bisa berperan pondasi yang kuat dugaan kurang dirinya di sepuluh dasawarsa yang akan datang. Salah esa hukum yang bisa dilakukan kepada melebarkan kecendekiaan emosional bani gasak adalah tambah menyematkan edukasi kelakuan. Hal ini sehala tambah haluan yang disampaikan oleh Agus Prasetyo dan Emusti Rivasintha (bagian dalam Kurniawan, 2013: 32) yang mengutarakan bahwa menyusuri edukasi kelakuan seorang kanak-kanak akan berperan cerdas emosinya.

\section{KESIMPULAN}

Karakter adalah suatu kebiasaan (habit) yang didalamnya terselip hukum berbicara dan berwatak yang menodong seseorang kepada bergaya dan berbuat di berbagai kondisi. Karakter bisa dibentuk menyusuri edukasi. Pendidikan kelakuan adalah reka yang dilakukan secara depan dan berniat kepada menyuntikkan etos-etos kelakuan dekat selira bani gasak. Nilai-etos terselip adalah etos religius, jujur, toleransi, disiplin, peranan keras, kreatif, mandiri, demokratis, penglihatan butuh tahu, roh kebangsaan, kama jagat air, mengambung-ambung prestasi, bersahabat/komunikatif, kama damai, suka sekali membaca, ingat lingkungan, ingat sosial, dan tanggung jawab. Pendidikan kelakuan harus dilakukan tambah berkelanjutan, etos-etos kelakuan terinternalisasi bagian dalam setiap beban moral yang dipelajari bani gasak, etos-etos kelakuan tidak racun ditangkap tambah sendirinya oleh bani gasak atau semata-mata sekedar diajarkan menyendirikan bani gasak harus meneliti sendiri (bani gasak terbabit berkelakuan bagian dalam kiat pembelajaran) dan kiat operasi edukasi kelakuan harus menyeret-nyeret bani gasak secara berkelakuan. Karakter menyimpan hubungan tambah semangat. Emosi diartikan serupa opini yang yang disertai tambah transmutasi kintil prilaku fisik. Kecerdasan emosional adalah kebolehan seseorang bagian dalam mengurus emosinya sehingga bisa diekspresikan tambah benar dekat kondisikondisi tertentu. Berikut penjuru-penjuru kecendekiaan emosional mengenali semangat selira, mengurus semangat, menggelorakan selira sendiri, memedulikan semangat kategori lain (belas kasih) dan memupuk aliansi. Berdasarkan definisi yang persangkaan di paparkan dekat ranting analisis di awal bisa disimpulkan bahwa kecendekiaan emosional bani gasak langgar pokok bisa dikembangkan menyusuri edukasi kelakuan karena rekayasa edukasi kelakuan akan mereka bani gasak yang menyimpan kecendekiaan emosional yaitu bani gasak yang mampu mengurus emosinya tambah hormat, menggelorakan selira, menyimpan penglihatan belas kasih dan memupuk aliansi hormat tambah kategori lain. 


\section{DAFTAR PUSTAKA}

Bariyyah, K \& Latifah, L. (2019). Kecerdasan Emosi Siswa Ditinjau Dari Jenis Kelamin Dan Jenjang Kelas. Jurnal Penelitian Guru Indonesia. 4 (2). 68-75. Goleman, Daniel. 1995. Emotional Intelligence. New York: Bantam Books.

Goleman, D. (2007). Emotional Intelligence, Kecerdasan Emosional Mengapa El Lebih Penting Dari IQ. Alih Bahasa: T Hermaya. Jakarta: PT Gramedia Pustakautama.

Indaayu, P. (2017). Peran Pendidikan Karakter Dalam Kecerdasan Emosional Siswa Sekolah Dasar. Prosiding Seminar Nasional Tahunan Fakultas IImu Sosial Universitas Negeri Medan. 1 (1). 344347.

Indriawati, P. (2018). Pengaruh Kepercayaan Diri Dan Kecerdasan Emosional Terhadap Hasil Belajar Mahasiswa Universitas Balikpapan. Jurnal Pendidikan Edutama. 5 (2). 1- 9.

Kemko Kesra RI. (2010). Kebijakan Nasional Pembangunan Karakter Bangsa. Jakarta.

Khodijah, Nyanyu. (2014). Psikologi Pendidikan. Jakarta: PT Raja Grafindo Persada.

Kurniawan, Syamsul. (2013). Pendidikan Karakter. Yogyakarta: Arruzmedia

Labudasari, E. \& Sriastria, W. (2020). Perkembangan Emosi Pada Anak Sekolah Dasar. Prosiding Seminar Nasional Pendidikan FKIP Universitas Muhammadiyah Cirebon.

Lawrence, R. L. (2017). Understanding Collaborative Leadership in Theory and Pratice. In adult Learning Through Collaborative Leardership (pp.89-96). Wiley Online Library. https://doi.org/10.1002/ace.20262

Lestari, P. (2021). Tingkat Kecerdasan Emosi Peserta Didik Kelas XI Di SMA Negeri 15 Palembang. Jurnal Konseling Koperhensif. 6 (1). 11-20.

Muslich, Masnur. (2014). Pendidikan Karakter Menjawab Tantangan Krisis Multidimensional. Jakarta: Bumi Aksara.

Primasari, G, at el. (2019). Pendidikan Karakter Bagi Generasi Masa Kini. Prosiding Seminar Nasional Pendidikan Program Pascasarjana Universitas PGRI Palembang.

Ramdhanti, M. (2019). Pembentukan Karakter Dalam Pembelajaran BCCT (Beyond Center And Circle Time). Jurnal Educate. 4 (1). 10-17.

Shapiro, Lawrence E. (1997). Menagajarkan Emotional Intellegence Pada Anak (Alih Bahasa Alex Tri Kantjono). Jakarta: Gramedia Pustaka Utama.

Sumantri, S. M. (2015). Pengantar Pendidikan. Hakikat Manusia Dan Pendidikan. MKDK4001/MODUL 1.

Utami, W. S. (2019). Penerapan Pendidikan Karakter Melalui Kegiatan Kedisiplinan Siswa. Jurnal Pendidikan. 4 (1). 63-66.

Zulaikah, S. (2019). Penguatan Pendidikan Pendidikan Agama Islam Di SMPN 3 Bandar Lampung. AlTadzkiyyah: Jurnal Pendidikan Islam. 10 (1). 83- 93. 